\title{
A Novel Design of Wideband Frequency Antenna for WLAN
}

\author{
Zhang Rongrong \\ Communication Engineering \\ Communication University of China \\ Beijing, China \\ zhangrongrong@cuc.edu.cn
}

\author{
Guan Yalin \\ Communication Engineering \\ Communication University of China \\ Beijing, China \\ ylguan@cuc.edu.cn
}

\begin{abstract}
A novel and simple coplanar waveguide (CPW)-fed monopole antenna with wideband dual-frequency is proposed in this paper. The proposed antenna printed and integrated on a small region of a microwave substrate has a compact size of $22 \times$ $35 \mathrm{~mm}^{2}$. This antenna, fed by CPW and connecting a $50 \Omega$ SMA connector, can generate two separate resonant frequency bands, which cover the 2.4-, 5.2-, and 5.8-GHz WLAN bands. This proposed antenna could present well impedance matching performance. The lower frequency mode of the proposed antenna has an impedance bandwidth (2:1 VSWR) of about 320 $\operatorname{MHz}(2380-2700 \mathrm{MHz})$, which covers the required bandwidth for 2.4-GHz WLAN band (2400-2484 MHz); on the other band, the upper frequency mode has a bandwidth of about $2480 \mathrm{MHz}$ (3580-6040 MHz) covering the HIPERLAN band (5150$5350 \mathrm{MHz}$ ) and 5.8-GHz WLAN band (5725-5852 MHz).Details of the design considerations for achieving dual-band operation are presented.
\end{abstract} profile

Keywords-CPW-fed; WLAN; wideband; dual-frequency; low

\section{INTRODUCTION}

In the recent years, the wireless communications community has seen an enormous opportunity to drive many wireless devices that could communicate over short distances. The wireless local area network (WLAN) is a most important part of wireless communication. Antennas, occupying a small volume of the system and good performance, are very attractive for WLAN. So there exist many different kinds of antenna designs, such as the planar inverted-F antennas (PIFAs) [1,2], the planar monopole antennas[3,4] and CPW-fed monopole antennas[5-9], which enable antennas with low-profile, lightweight, flush mounted and single-feed to fit the limited equipment space of the WLAN devices. Among these antennas, the planar monopole antennas have especially received much more interest than others owing to their potential in providing various required radiation features of dual-band or multiband, wide bandwidth, and low profile for a communication system. However, such kinds of antennas mostly need a large size of ground plane, which is often printed on the different side of the substrate from the radiating plane, and thus a via-hole connection is always necessary for feeding the signal and this increases the manufacture difficulty and cost.

Recently, a great interest in coplanar waveguide (CPW)-fed antennas has been found because of their many attractive features such as wider bandwidth, better impedance matching, simplest structure of a single metallic layer, no soldering point, and easy integration with active devices or monolithic microwave integrated circuits (MMICs) [5]. For the available designs, the CPW-fed square slot antenna reported in [6] is capable of broad but single-band operation only, and the CPWfed inductive slot antennas reported in [7] are capable of dual or multiband operation for WLAN operations. However, they do not have broad bandwidths and require greater complexity of antenna shape. Both of [8] and [9] have presented much simpler CPW-fed notched monopole antennas with enhanced bandwidth and are suitable for WLAN $2.4 / 5.2 \mathrm{GHz}$ dual-band operations. However, the antenna size, including the ground planes, is quite large to occupy much of the device space.

In this paper, a novel and simple wideband dual-frequency design of CPW-fed monopole antenna is presented. The antenna is fed by a CPW line so that only a single-layer substrate is required for this antenna. By comparison with literature [5-9], the antenna, with a different radiation patch, has not only smaller size but also wider bandwidth and better impedance matching. Details of the antenna design are described in the next.

\section{ANTENNA DESIGN}

Fig. 1 shows the geometry of the proposed antenna design, which can provide the dual-band operation with good impedance matching. The antenna's radiation element and ground plane are etched on the inexpensive FR4 substrate of $1.6 \mathrm{~mm}$ thickness and 4.4 in relative permittivity, while the other side is without any metallization. A CPW transmission line, which is made up of a signal strip thickness $W_{3}$ and a gap distance of $W_{4}$ between the signal strip and the coplanar ground plane, connects $50 \Omega$ SMA connector to feed the antenna. The size of $W_{3}$ and $W_{4}$ determines the characteristic impedance of the CPW feed line. Two equal finite ground planes, each with dimension of length $L_{2}$ and width $W_{2}$, are symmetric on each side of the CPW-fed line. To reduce the antenna size and also maintain good performance as largely as possible, the L-shape array radiation patches are taken. Finally, the antenna size is successfully reduced to $22 \times 35 \mathrm{~mm}^{2}$, which can satisfy the demand of smaller and smaller devices. 


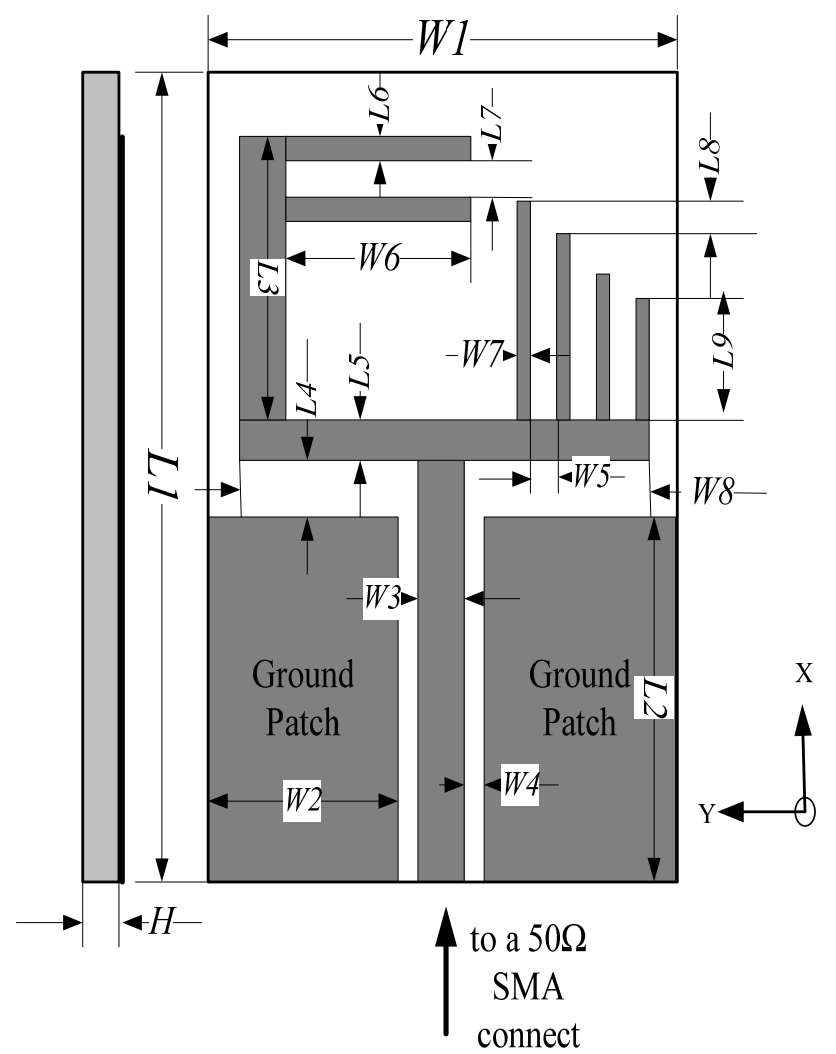

Figure 1. Geometry of the wideband dual-frequency antenna. The dimension (in millimeters) shown in the figure is not to scale.

For the antenna design shown in the Fig. 1, the basis of the antenna structure can be divided into two parts by the end of the CPW feed line, the left part and the right part. The left part has three horizontal length $\left(W_{6} \times 2, W_{8} / 2\right)$ and a vertical height $\left(L_{3}\right)$, while the other one is with a horizontal length $\left(W_{8} / 2\right)$ and four vertical height. Because of the two sections, the antenna can generate two separate resonant frequency bands. The two elements can resonate as a monopole antenna with their respective length determined by nearly one-quarter wavelength. The length $\left(L_{9}+W_{8} / 2\right)$ of the right part decides the upper resonant frequency $(4.82 \mathrm{GHz})$, while the length $\left(L_{3}+W_{6}+W_{8} / 2\right)$ of the other is chosen from the lower resonant point $(2.54 \mathrm{GHz})$.Probably owing to the coupling of the two elements, the resonant length of the left element can be reduced. To get wider bandwidth and improve the radiation pattern, similar rectangular patches are used. To investigate the performance of the proposed antenna configuration in terms of achieving the wideband dual-frequency operations, electromagnetic analysis tool, GEMS, is used for required numerical analysis and obtaining the proper geometry parameters. With carefully modulation, the finally optimal dimensions are obtained to be $L_{1}=35 \mathrm{~mm}, L_{2}=17 \mathrm{~mm}, L_{3}=9 \mathrm{~mm}$, $L_{4}=3 \mathrm{~mm}, \quad L_{5}=2 \mathrm{~mm}, \quad L_{6}=0.75 \mathrm{~mm}, \quad L_{7}=1 \mathrm{~mm}, \quad L_{8}=0.5 \mathrm{~mm}$, $W_{1}=22 \mathrm{~mm}, W_{2}=8.9 \mathrm{~mm}, W_{3}=3 \mathrm{~mm}, W_{4}=0.6 \mathrm{~mm}, W_{5}=1 \mathrm{~mm}$, $W_{6}=8 \mathrm{~mm}, W_{7}=0.5 \mathrm{~mm}, W_{8}=20 \mathrm{~mm}$ and $H=1.6 \mathrm{~mm}$.In the following section, the influence of different parameters is discussed.

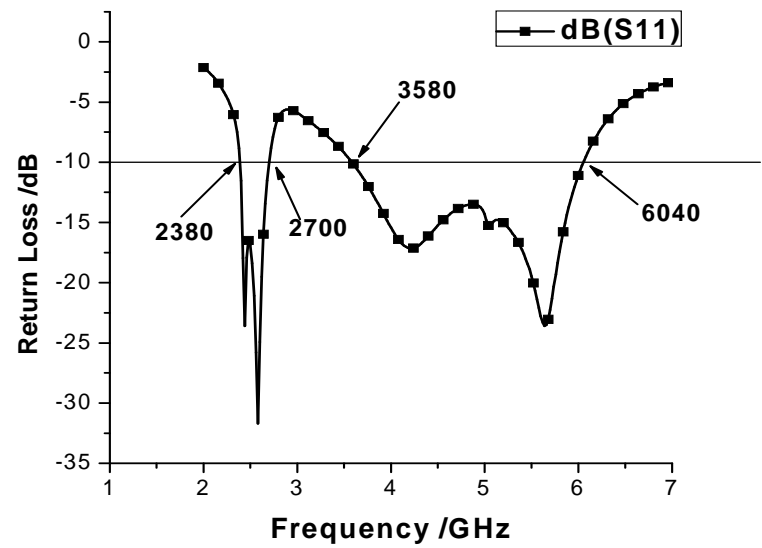

Figure 2. Return loss for the antenna of the figure 1 optimised from the simulation software GEMS with $L_{1}=35 \mathrm{~mm}, L_{2}=17 \mathrm{~mm}, L_{3}=9 \mathrm{~mm}, L_{4}=3 \mathrm{~mm}$, $L_{5}=2 \mathrm{~mm}, L_{6}=0.75 \mathrm{~mm}, L_{7}=1 \mathrm{~mm}, L_{8}=0.5 \mathrm{~mm}, W_{1}=22 \mathrm{~mm}, W_{2}=8.9 \mathrm{~mm}$, $W_{3}=3 \mathrm{~mm}, W_{4}=0.6 \mathrm{~mm}, W_{5}=1 \mathrm{~mm}, W_{6}=8 \mathrm{~mm}, W_{7}=0.5 \mathrm{~mm}, W_{8}=20 \mathrm{~mm}$ and $H=1.6 \mathrm{~mm}$.

\section{RESULTS AND DISCUSSION}

Fig. 2 shows return loss of the antenna with the optimal parameters against frequency. It is clearly seen that two wide operating bandwidths are obtained. The lower bandwidth, determined by $-10 \mathrm{~dB}$ impedance bandwidth, reaches $320 \mathrm{MHz}$ $(2380-2700 \mathrm{MHz})$ and covers the 2.4- GHz WLAN band $(2400-2480 \mathrm{MHz})$. On the other hand, the upper band has a bandwidth as larger as $2480 \mathrm{MHz}(3580-6040 \mathrm{MHz})$ and covers other WLAN bands at $5.2-\mathrm{GHz}(5150-5350 \mathrm{MHz})$ and 5.8- $\mathrm{GHz}(5725-5852 \mathrm{MHz})$.

In the table 1, the two parameters, $L_{4}$ (the distance between ground patch and horizontal radiation patch) and $W_{5}$ (the space between the vertical patches of the right radiation element), have different effect on the impedance bandwidths. Different dimensions of $L_{4}$ do influence the bandwidth while $W_{5}$ almost has no effect on it. Moreover, only if the value of $L_{4}$ equals $3 \mathrm{~mm}$, the lower bandwidth can satisfy the $2.4-\mathrm{GHz}$ WLAN band. The reason is that the change of the length $L_{4}$ impacts the coupling effects between the radiation elements and ground patch to affect the isolation and input impedance of the end feeding port.

TABLE I. RESULTS OF THE PROPOSED ANTENNA BY VARYING DISTANCE $\mathrm{L}_{4}$ AND $\mathrm{W}_{5}$ AND OTHER PARAMETERS ARE THE SAME AS IN THE FIGURE 2.

\begin{tabular}{|c|c|c|c|c|}
\hline & $\boldsymbol{L}_{\mathbf{4}} / \mathbf{m m}$ & $\boldsymbol{W}_{5} / \mathbf{m m}$ & $\mathbf{B W} / \mathbf{G H z}$ & $\mathbf{B W} / \mathbf{G H z}$ \\
\hline 1 & 3 & 0.5 & $2.4-2.72$ & $3.6-6.04$ \\
\hline 2 & 3 & 1 & $2.38-2.7$ & $3.58-6.04$ \\
\hline 3 & 3 & 1.5 & $2.4-2.68$ & $3.62-6.04$ \\
\hline 4 & 2 & 1 & $2.5-2.68$ & $4.02-6.26$ \\
\hline 5 & 4 & 1 & $2.42-2.72$ & $3.44-6.0$ \\
\hline
\end{tabular}


The effect of the horizontal part $\left(W_{6}\right)$ of the left radiation element on the performance of the proposed antenna is also studied and presented in figure 3 .

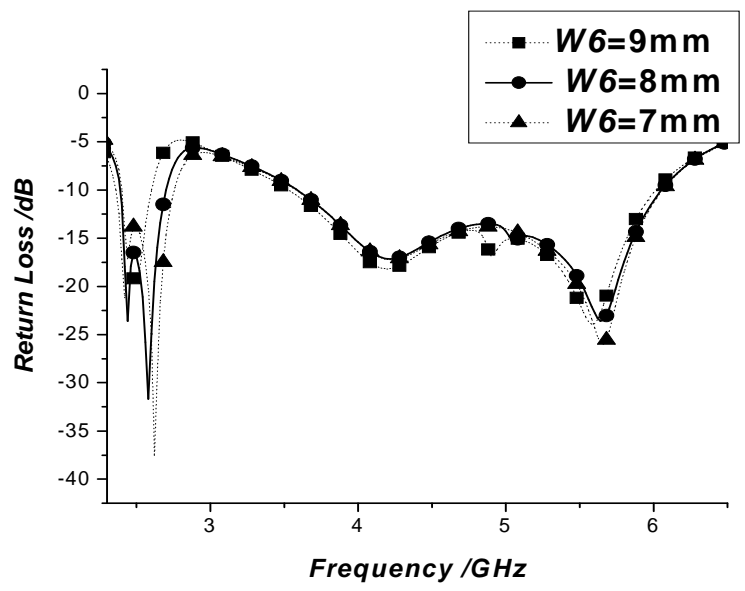

(a)

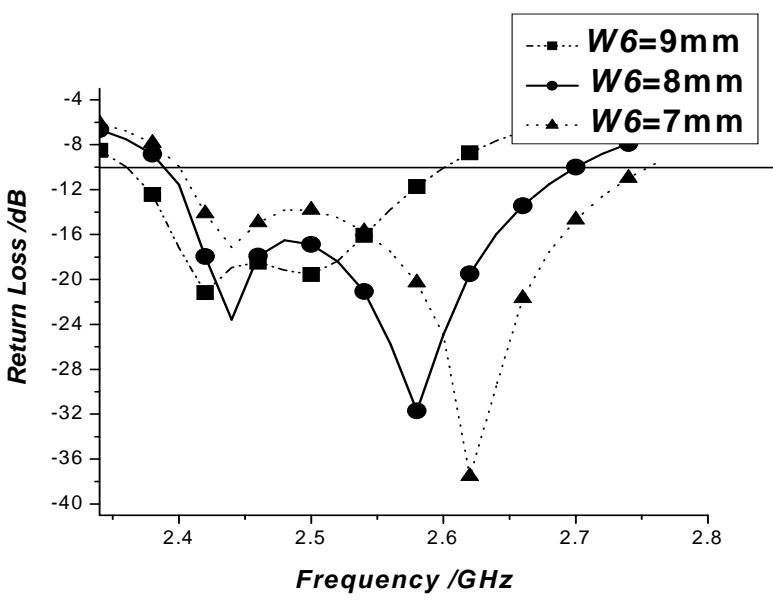

(b)

Figure 3. (a)Return loss against frequency for the proposed antenna with various length $\left(W_{6}\right)$.Other parameters are the same as in Fig. 2. (b) to enlarge picture (a) in frequency from $2.34 \mathrm{GHz}$ to $2.8 \mathrm{GHz}$.

When the dimension of $W_{6}$ is $9 \mathrm{~mm}$, the lower resonant bandwidth isn't as good as when $W_{6}=8 \mathrm{~mm}$. However, When W6 equals $7 \mathrm{~mm}$, the lower bandwidth don't cover the $2.4-\mathrm{GHz}$ band. The radiation patterns of the proposed antenna for the case of the parameters in Fig. 2 are shown in Fig. 4, 5, 6. Fig. 4, 5,6 , respectively, plot the radiation patterns at 2.44, 5.2 and $5.8 \mathrm{GHz}$. It is can be seen that the obtained radiation patterns are not as good as those of a conventional ideal monopole antenna, which has a good omnidirectional pattern. However, the proposed antenna shows a nearly omnidirectional radiation in the $\mathrm{Y}-\mathrm{Z}$ plane at each frequency, which is vertical with the surface of substrate (X-Y plane).

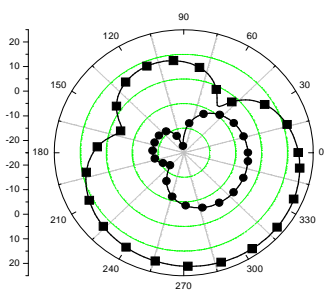

(a)

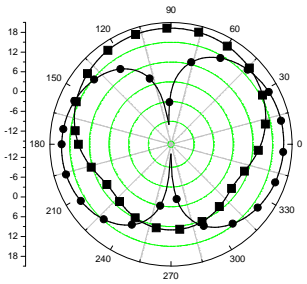

(b)

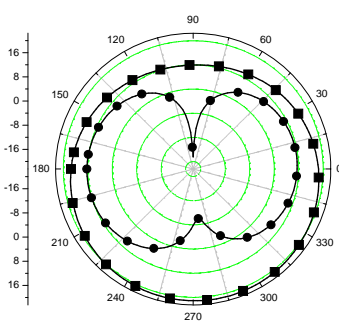

(c)

Figure 4. Radiation patterns for the proposed antenna studied in figure 2 at 2.44GHz (a)X-Y plane (b)Z-Y plane (c) Y-Z plane

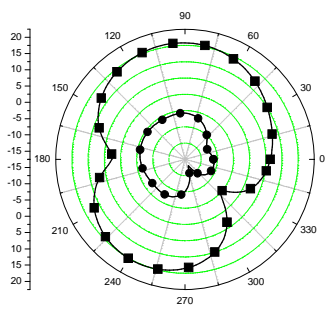

(a)

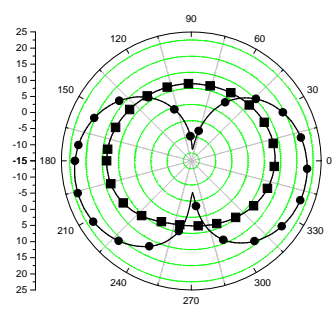

(b)

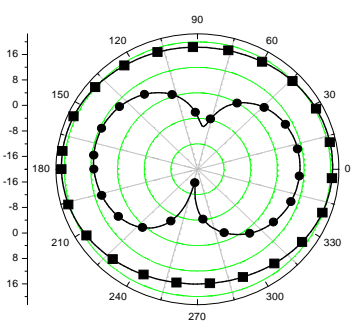

(c)

Figure 5. Radiation patterns for the proposed antenna studied in figure 2 at 5.2GHz. (a)X-Y plane (b)Z-Y plane (c) Y-Z plane

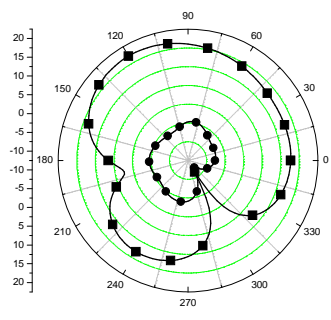

(a)

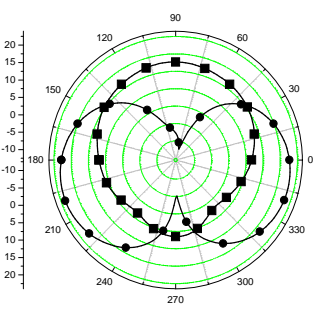

(b) 

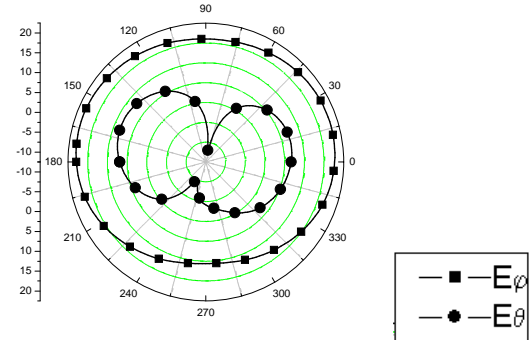

(c)

Figure 6. Radiation patterns for the proposed antenna studied in figure 2 at 5.8GHz. (a)X-Y plane (b)Z-Y plane (c) Y-Z plane

\section{CONCLUSION}

A novel and simple CPW-fed monopole antenna for broadband dual frequency operation has been presented. The antenna, covering the WLAN bands (2.4-, 5.2-, 5.8-), successfully realizes smaller and wider bandwidth. Though its size, $35 \times 22 \mathrm{~mm}^{2}$, is very small, the radiation patterns are good. In addition, the effects of varying antenna parameters on the resonant frequencies and impedance bandwidth have also been studied. By using a suitable structure of the radiation elements, the diversity antenna for WLAN with similar performances as the proposed antenna could been obtained.

\section{REFERENCES}

[1] Salonen P, Keskilammi M and Kivikoski M, "New slot configurations for dual-band planar inverted-F antenna", Microw. Opt. Technol. Lett., vol. 28, pp. 293-298, 2001.

[2] Hsiao F R and Wong K L, "ompact planar inverted-F patch antenna for triple-frequency operation", Microw. Opt. Technol. Lett.,vol. 33, pp. 459-462, 2002.

[3] Kuo Y L and Wong K L, "Printed double-T monopole antenna for 2.4/5.2GHz dual-band WLAN operations", IEEE Trans. Antennas Propag., vol. 51, pp. 2187-2192, 2003.

[4] Lee L S, Hall P S and Gardner P, Electron. Lett., vol. 35, pp. 2157-2158, 1999.

[5] Ip K.H.Y., Kan T.M.Y. and Eleftheriades G.V., “'A single-layer cpw-fed active patch antenna", IEEE Microw. Guid. Wave Lett., vol. 10, pp. 6466, 2000.

[6] Lin X C and Wang L T, "A broadband cpw-fed loop slot antenna with harmonic control”, IEEE Antennas Wirel. Propag. Lett., vol.2, pp. 323325, 2003.

[7] Angelopoulos E.S., Stratakos Y.E., Kostaridis A.I., Kaklamani D.I., and Uzunoglu N.K., "Multiband miniature coplanar waveguide slot antennas for GSM-802.11b and 802.11b-802.11a wireless applications", IEEE Wirel. Commun. Netw., vol. 1, pp. 103-108, 2003.

[8] Liu W C and Wu C M, "Broadband dual-frequency cpw-fed planar monopole antenna with rectangular notch", Electron. Lett., vol. 40, pp. 642-643, 2004.

[9] Liu W C, "Wideband dual-frequency double inverted-L CPW-fed monopole antenna for WLAN application", IEEE Proc. Microw. Antennas Propag., 2005. 